05

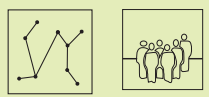

\title{
SINO - FRENCH COOPERATION
}

\section{Cultural Heritage and Rural Area Development In Guizhou Province}

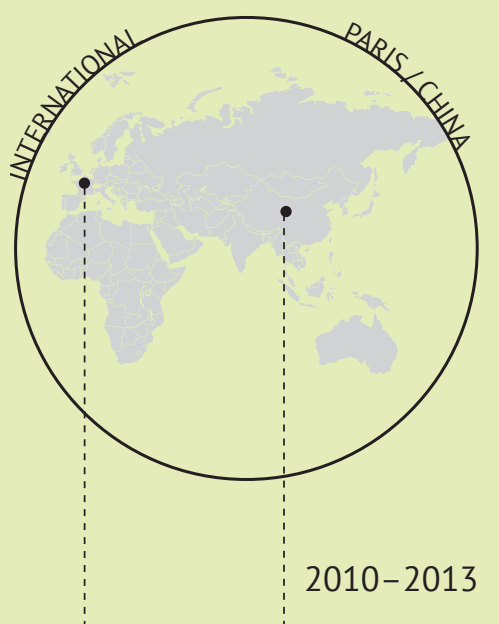

Organisations + Collaborators
Regis Ambroise, Guy Amsellem
Annie Bergeret Curien, Anthony
Chaumuzeau,
Mireille Grubert,
Isabelle Maréchal,
Benjamin Mouton,
Alain Marinos, Jacques Mayoud
Emilie Rousseau, Luc Savonnet
Alain Vernet, Chang Qing
Du Kexin, Lu Wei, Ren Hexin,
Shao Yong, Qu Ying
Wang Hongguang, Zhang Peng,
Zhou Jian

\section{Introduction}

Building on a long-standing relationship between urban planners at the Tongji University in Shanghai and professionals from different public sectors selected by the Observatoire de l'architecture de la Chine contemporaine ${ }^{1}$ in France, a cooperation on the role of culture in developing rural villages in Guizhou province in China was kicked off in 2008 by the invitation of the Guizhou Province Bureau of Culture. Thereby, the aim was to develop a holistic approach to enhance the protection of natural and cultural landscape, including social and economic issues. Our common aim was to promote a sustainable development, while considering that the tourism industry could not be the main support.

Indeed, the province of Guizhou, with its 40 million inhabitants, is largely rural, due to its mountainous land, and has therefore avoided our contemporary way of life for a long time. The mountains of this province have provided a refuge for many ethnic groups (Dong, Miao, Buyi, Yao, etc.), who

FIGURE III.5.1 Dimen village, view from the river. Granary in the foreground, houses on the hill. Photo by Françoise Ged. 
have all developed a rich natural, cultural and intangible heritage. These villages were relatively autonomous until the beginning of the 21st century, up to the arrival of highways, railways and airports, which led to the fact that most of the villages could then be reached from large Chinese cities within a few hours, rather than days. Each village's exceptionally rich culture is now experiencing growing domestic tourism, which creates jobs and economic growth, but also threatens to upset the balance of these traditionally circular and environmentally friendly economies. How to find a balance between economic development and the proper enhancement of the exceptionally rich culture and way of life?

From the beginning, an incremental approach was developed, which seems appropriate to the rapid economic and social changes in China and to variations of the possibility of financing actions in China or organising professional training to France. Between 2010 and 2013, an integrative approach combining arts and humanities was developed and practised. For example, a programme with photographers was organised, aiming at providing their personal insights about natural and cultural heritage in Guizhou province, paying special attention to giving respect and dignity to places and people in their daily life and know-how. With the support of the program Archives on Recent Past, two photographers, one Chinese and the other living in France, were asked to reveal their perception of heritage in rural places. The results were shown in an exhibition and disseminated in publications.

Another example is the Sino-French seminar, which was organised in summer 2013 in Guizhou. It gathered experts from built heritage, architecture, ethno-musicology, textiles, agronomy, writers, museology and administration in order to exchange information about best practices. A short documentary was realised, presenting the advantage of interdisciplinary work, upstream of the project to be carried out. ${ }^{2}$

This approach aimed to facilitate mutual learning and revealed to the participants the importance of combining disciplinary perspectives. Mutual learning and understanding across cultures and language divides was further enhanced by horizontal exchanges offering the opportunity to pursue the dialogue in each of these fields, through different workshops. Then, a final meeting in France provided the opportunity of sharing information with a broader audience about cultural and natural heritage protection, urban tools and urban development processes among decision-makers and local authorities from both China and France.

In fact, the rapid development of the last two decades has severed the link between nature and culture, changing conditions of life with a richness of culture disappearing quickly. What are the best tools, for example, to support the disappearing knowledge in the local language about songs, embroidery, dyeing, medicinal plants and health care, etc. which are not important in primary school education? How does one maintain the memory of this very holistic way of life?

In France, we established an institutional blog on the French National Scientific Research Centre $(\mathrm{CNRS})^{3}$ portal, on the basis of photographs and meta-data, where we could organise the materials collected through seminars, study visits, music recordings and photography, in order to gather appropriate information and comment on all we have produced.

\section{The Actors}

The Chinese and French parties already have 20 years' experience of common engaged practice. On the Chinese side, the team is composed of urban planners from Tongji University who are both practitioners and academics. They have access to national or international research action 


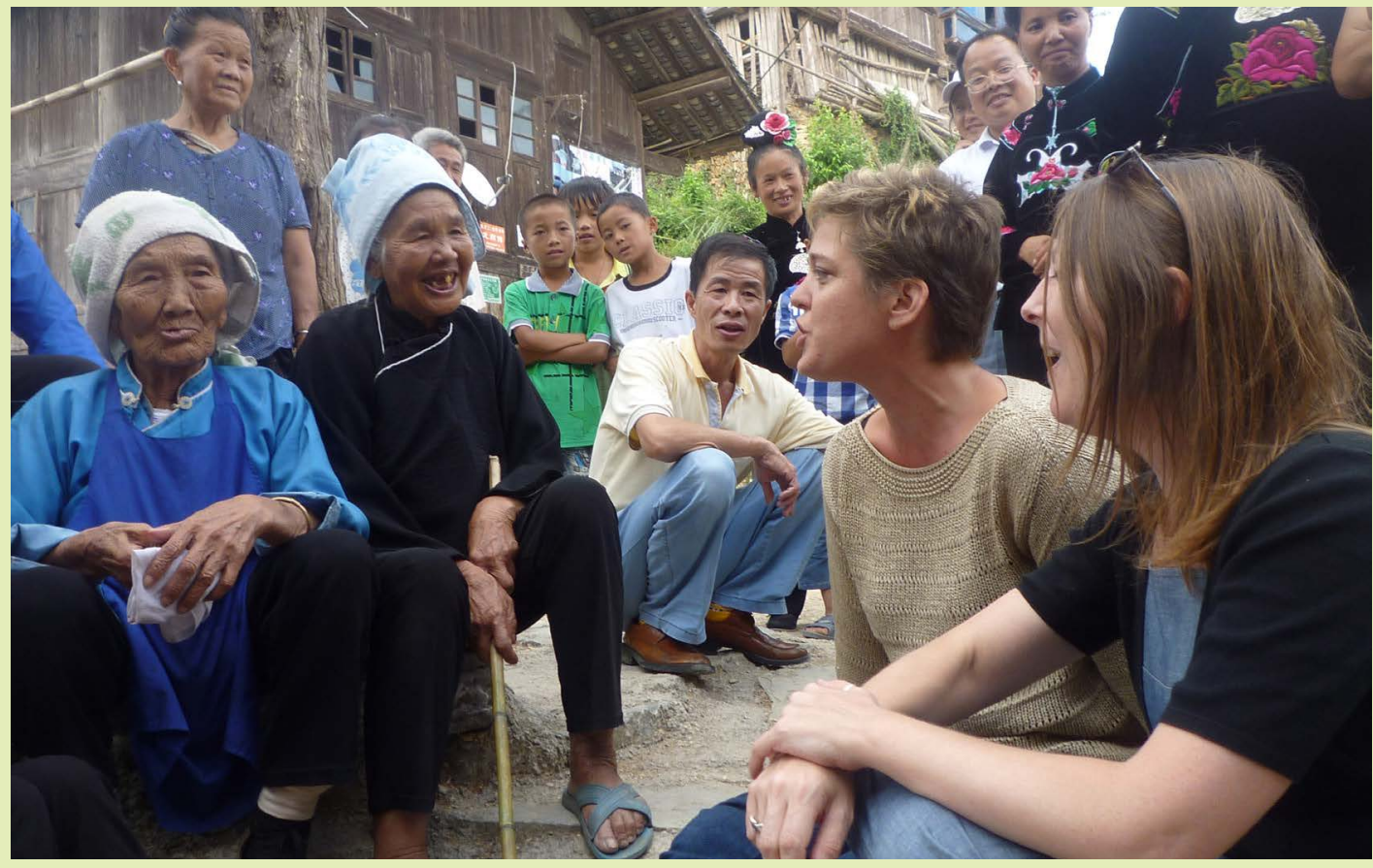

FIGURE III.5.2 Kongbai village, old women and French ethnomusicologists sharing songs. Photo by Emilie Rousseau

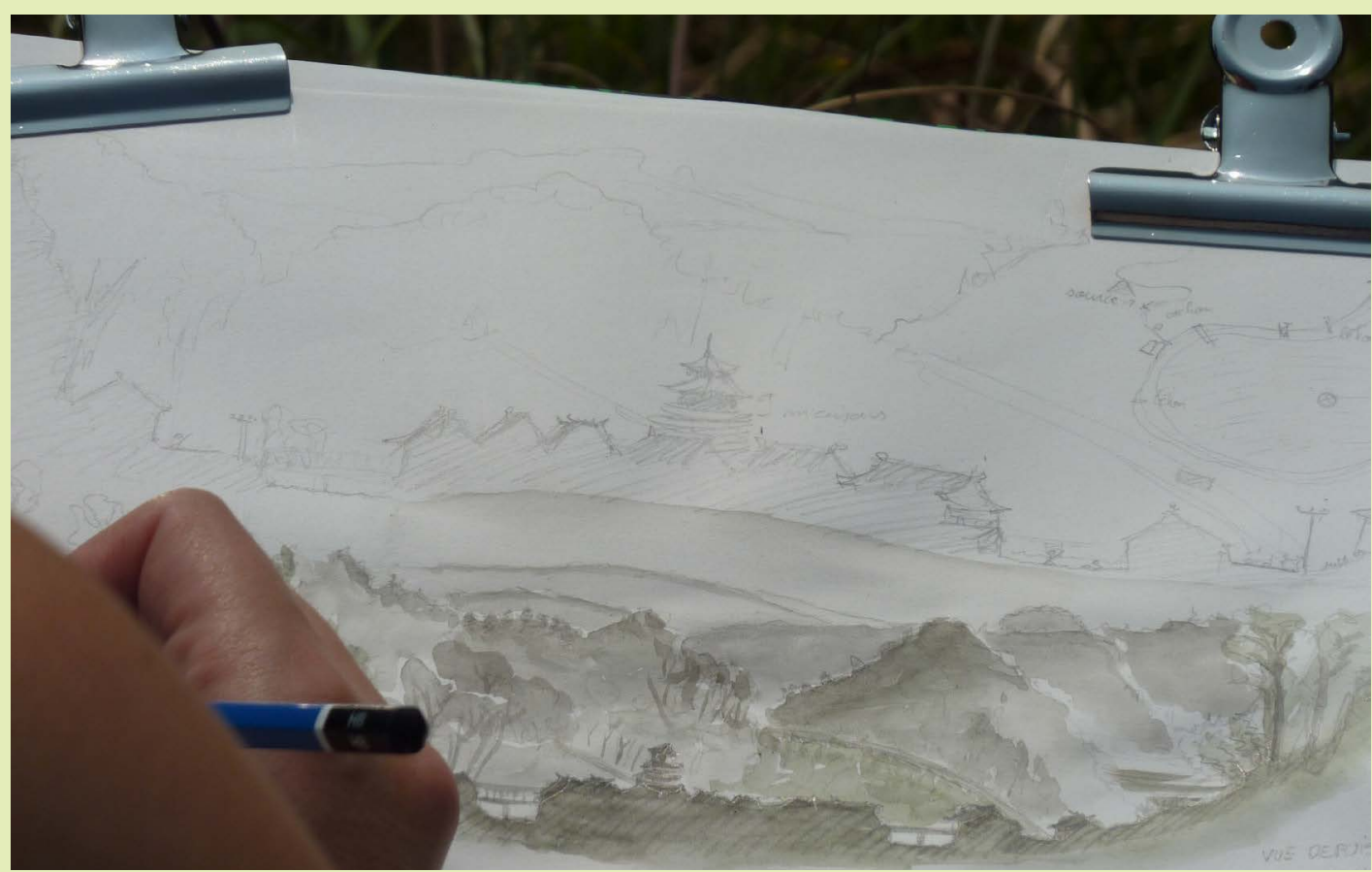

FIGURE III.5.3 Drawing of a French student, participant of the joint workshop between Tongji university and École de Chaillot in Zenchong village. Photo by Françoise Ged 


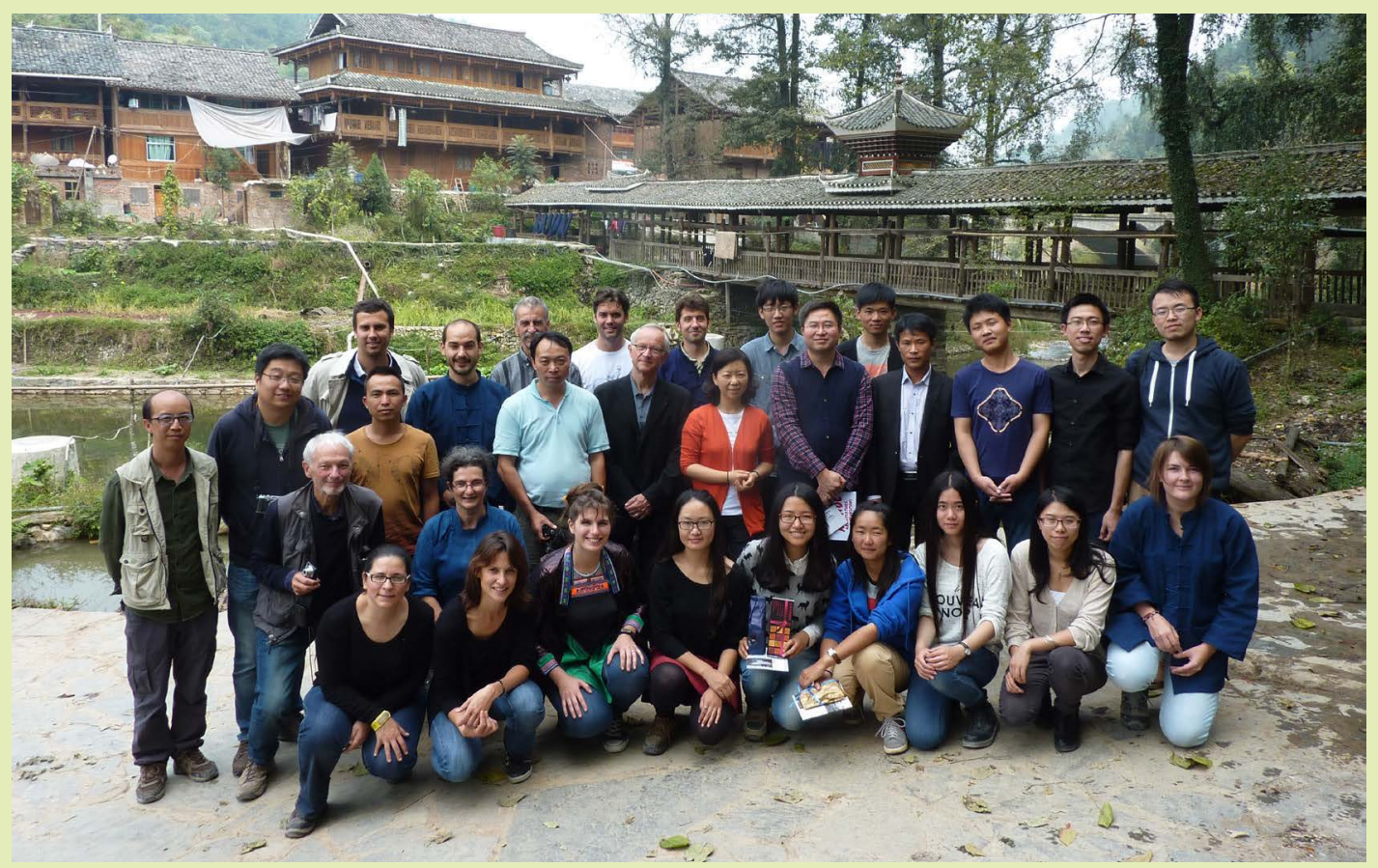

FIGURE III.5.4 Zenchong village, students and professors of the joint workshop between Tongji university and École de Chaillot. Photo by Françoise Ged

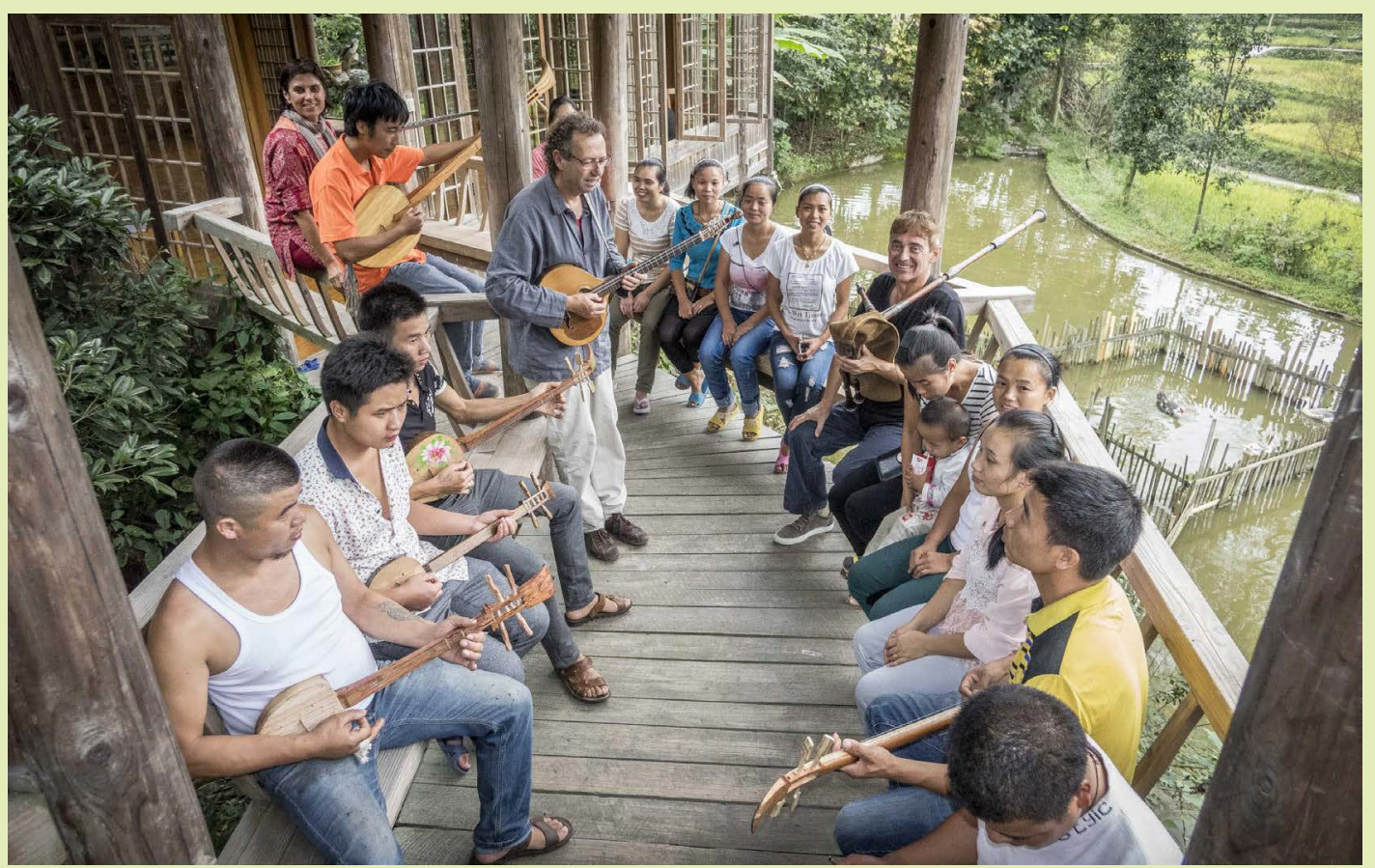

FIGURE III.5.5 Residency of French musicians and researchers in Dimen village. Photo by Fabien Da Costa 
projects, as in Guizhou province, by working with national policy makers, regional directors and local authorities. Our main partners, Prof. Zhou Jian, Prof Shao Yong and Prof Ruan Yisan have contributed to establish the World Heritage Institute for Training and Research - Asia Pacific ${ }^{4}$ (WHITRAP), created under the auspices of the United Nations Educational, Scientific and Cultural Organization in 2006. In addition, various actions have been organised in Guizhou province and in France with the Culture Bureau of Guizhou province, with the academic fields, with Dimen Ecomuseum which is an interesting structure partly financed by the Culture Bureau of Guizhou, as well as with cultural associations and other experts on the French side.

\section{The Challenges of the Project}

Several challenges were encountered during the duration of the cooperation. The first is the different institutional logics and standards in the two countries. The starting point of the Sino-French cooperation is based on urban heritage protection and regulations. On the Chinese side, urban heritage protection policy in cities and now in rural areas was then mainly under the supervision of the Ministry of Housing, Urban and Rural Development (MOHURD), previously the Ministry of Construction, which had a mutual agreement with its French counterpart, but not with the French Ministry of Culture. But, in France, the protection of built heritage in cities and protected areas is conducted by the State Architects and Urban Planners, who are experts under the auspices of the Ministry of Culture. Because of this difference of status in the two countries, we have to face the difficulty of competition between the ministries rather than building bridges according to the common topics of protection and urban planning. On an individual level, however, the Chinese and French experts involved had the competences and disposition to overcome this barrier and to continue the programme. A second challenge is that interdisciplinary research is not so common in the Chinese context and requires a lot of work from our Chinese partners. Our cooperation, however, led to an increased understanding of the connection between rural and urban development by both partners, and thus offered enthusiastic aspiration for an interdisciplinary approach by the different people involved in the process.

So, are we ready to shift paradigm? The comprehensive approach of the questions we encounter in Guizhou province require us to avoid the predominance of a specific discipline and to take more time to listen to the different experts, the practitioners, the local population and the local government. This approach requires that all participants share the same objective, the same vision. It is, however, difficult to reach a common objective, if you do not see it or you are not able to share it. How to overcome this barrier? Only by encouraging long-term processes, with the support of education and mutual learning through experimentation, can this barrier be conquered. A long-term process requires funding and institutional support, which leads to the third challenge we want to raise awareness about: limited access to funding. During the 20 years of cooperation, we have tried to seek financial resources according to opportunities and national policies. Currently, the Chinese side provides the fees for accommodation and transport in China and we do the same on the French side. Because of the Chinese economic growth, their needs and the funding required are different: during the first ten years, the French side gave support for scholarships and internships for young researchers for six months or one year for inviting the Chinese experts and the local authorities' representatives. Gradually, the Chinese side need more experts to go to China, and take responsibility for more fees, including international transport and accommodation. On the French side, after a period with good support from the French embassy, we are trying to implement regional-level cooperation with China, as decentralised cooperation between cities begins to be more important. After investigations 
in France, we identified different structures that could have suitable experts who could share their knowledge with our Chinese partners. However, the barrier is in establishing a link between institutions and structures, to create transdisciplinary processes between institutions, associations and professional structures from different places.

\section{What Have We All Learnt Together?}

One important result was a half-day meeting of the Guizhou project, with all the disciplines involved gathering in Paris, including Chinese and French speakers, who have discovered that they could interest numerous and varied publics.

First of all, we learnt on both the Chinese and French sides the importance of mutual confidence and the length of time required in the cooperation process. We could pursue experimentation through different phases, in Guizhou province as well as in different rural areas in China, where similar questions are hot topics. Then, by organising field seminars and workshops, with students from China and France, with local inhabitants and with the support of regional authorities, we will take steps for the following generations, trying to create links between different disciplines and universities. We are giving opportunities for the exchange of information on best practices and for the sharing of new viewpoints, methodologies and analyses. 


\section{Notes}

1 At "Cité de l'architecture et du patrimoine" - a cultural public institution under the auspices of the French Ministry of Culture.

2 https://www.youtube.com/watch?time_continue $=6 \& \mathrm{v}=\mathrm{WWf}$ WwETbbY\&feature $=$ emb_title

3 2019: https://didomena.ehess.fr/collections/bv73c054d?locale $=$ fr

4 http://www.whitr-ap.org/ 